\title{
Infestation and distribution of chigger mites on Brown rat (Rattus norvegicus) in Yunnan Province, Southwest China
}

\author{
Ding, F. ${ }^{1}$, Guo, X.G. ${ }^{1 *}$, Song, W.Y. ${ }^{1}$, Fan, R. ${ }^{1}$, Zhao, C.F. ${ }^{1}$, Mao, K.Y. ${ }^{1}$, Zhang, Z.W. ${ }^{1}$, Peng, P.Y. ${ }^{1}$, Lin, H. ${ }^{1}$, \\ Dong, W.G. ${ }^{1}$, Qian, T.J. ${ }^{1}$, Yang, Z.H. ${ }^{1}$, Zou, Y.J. ${ }^{1}$ \\ ${ }^{1}$ Institute of Pathogens and Vectors, Yunnan Provincial Key Laboratory for Zoonosis Control and Prevention, Dali University, Dali, Yunnan, 671000, \\ China \\ *Corresponding author: xianguoguo@yahoo.com
}

\section{ARTICLE HISTORY}

Received: 6 April 2020

Revised: 23 November 2020

Accepted: 24 November 2020

Published: 25 March 2021

\begin{abstract}
Chigger mites is a group of arthropods and some of them are vectors of scrub typhus. As a common synanthropic rodent species, the Brown rat (Rattus norvegicus) often harbors lots of ectoparasites including chigger mites. According to some "data mining" strategies, the present study took the advantage of the abundant original data from a long-term field ecological investigation between 2001 and 2015 to make a detailed analysis of chigger mites on R. norvegicus in Yunnan Province, Southwest of China. From 18 of 33 investigated counties, only 1414 chigger mites were collected from 1113 Brown rats with relatively low infestations. The 1414 individual chigger mites were identified as comprising 61 species, 11 genera and 2 subfamilies of the family Trombiculidae with a high species diversity $\left(S=61, H^{\prime}=3.13\right)$. Of 61 mite species, there were four main species, Walchia ewingi, Ascoschoengastia indica, W. koi and A. rattinorvegici, which accounted for $44.41 \%$ of the total mites. All the chigger mites were of aggregated distribution among different individuals of $R$. norvegicus. The Brown rats in the outdoor habitats harbored much more individuals and species of chigger mites with a higher mean abundance $(M A=1.46)$ and mean intensity $(M I=12.53)$ than in the indoor habitats $(P<0.05)$. The overall infestation of the rats was significantly higher in the mountainous landscapes than in the flatland landscapes $(P<0.001)$. The species similarity $\left(C_{s s}\right)$ of the mites on the male and female rats reached $64.44 \%$ with sex biased infestations. The male rats harbored more species and individuals of the mites than the female rats. The adult rats harbored more species and individuals of the mites than the juvenile rats. The species abundance distribution of the mites was successfully fitted by Preston's lognormal model with $\hat{S}(R)=15 e^{-[0.31(R-1)]^{2}}\left(\alpha=0.31, R^{2}=0.95\right)$. On the basis of fitting the theoretical curve by Preston's model, the total mite species on $R$. norvegicus was estimated to be 86 species, and 25 rare mite species were missed in the sampling field investigation. The curve tendency of the species-plot relationship indicates that $R$. norvegicus have a great potential to harbor many species of chigger mites, and more species of the mites would be collected if more rats are sampled.
\end{abstract}

Keywords: Chigger mites; Scrub typhus; Brown rat; Ecology; Yunnan; China.

\section{INTRODUCTION}

As a group of arachnids, chigger mites belong to two families of Acari, Trombiculidae and Leeuwenhoekiidae (Zhan et al., 2013; Ren et al., 2014; Huang et al., 2017). There are a few common names for the chigger mites such as trombiculid mites, tsutsugamushi mites, chiggers, chigoes, redbugs, sand mites, harvest mites, grass itch mites and scrub itch mites, but "chigger mites" is the most frequent in scientific literature (Zhan et al., 2013; Peng et al., 2016b; Lv et al., 2018). Chigger mites are of significant medical and veterinary importance and some of them are vectors of scrub typhus (tsutsugamushi disease), an acute febrile zoonosis caused by Orientia tsutsugamushi (Candasamy et al., 2016; Samuel et al., 2017). There are more than 3000 known species of chigger mites worldwide and over 510 species in China (Guo et al., 2006; Duan et al., 2009; Ren et al., 2014; Ding et al., 2020). To date, there have been 274 species of chigger mites documented in Yunnan Province of Southwest China, which accounts for $53.73 \%$ of all the species recorded in China (274/510). The 274 species of chigger mites recorded in Yunnan belong to 26 genera and 2 families (Trombiculidae and Leeuwenhoekiidae), and the most species (109 species) belong to the genus Leptotrombidium of the family 
Trombiculidae (Wen, 1984; Li et al., 1997; Peng et al., 2016a). In the complex life cycle of chigger mites, only larvae (chiggers) are ectoparasites of mammals, aves, reptiles, amphibians and rarely arthropods (Axman \& Brummer, 2003; Huang et al., 2017). Rodents and some other small mammals (e.g. insectivores) are the most common hosts of chiggers (Lee et al., 2014; Candasamy et al., 2016). The attachment of chiggers to human skin can directly lead to dermatitis. Through the parasitism of chiggers and the transovarial transmission of the pathogen, scrub typhus can be transmitted from rodents to humans (Lee et al., 2014; Samuel et al., 2017). Scrub typhus is widely distributed in the socalled "Tsutsugamushi Triangle" regions including South, East, and Southeast Asia, Northern Australia and Pacific islands. In recent years, the incidence of scrub typhus has rapidly increased in many countries (Yao et al., 2019). Scrub typhus is prevalent in many parts of China, especially in the South and Southwest. Located in the Southwest China, Yunnan Province is an important focus of scrub typhus with 116 counties reporting the disease cases (Ya \& Zhang, 2016; Sun et al., 2018). Besides being the exclusive vector of scrub typhus, some chigger mites are considered as the potential vectors of hemorrhagic fever with renal syndrome (HFRS) caused by hantavirus (Wu et al., 1996; Yu \& Tesh, 2014). Yunnan Province is also an important epidemic focus of HFRS (Ya \& Zhang, 2016; Peng et al., 2017).

The Brown rat or Norway rat, Rattus norvegicus (Berkenhout, 1769), is a very common synanthropic rodent species (Rothenburger et al., 2015; Castillo \& Paller, 2018), and it is one of dominant rodent species in Yunnan Province (Peng et al., 2017). Besides being a very harmful pest in agriculture (Feng \& Himsworth, 2014; Rothenburger et al., 2015), R. norvegicus is also a very important reservoir host and infectious source of scrub typhus, HFRS and some other zoonoses (Walsh, 2014; Liu et al., 2017; Liu et al., 2020). Rattus norvegicus often harbors lots of ectoparasites including chigger mites (Schoof, 1948; Guo et al., 2016; Alonso et al., 2019).

From a long-term field investigation between 2001 and 2015 in Yunnan Province, abundant original data were successively accumulated and 1113 Brown rats ( $R$. norvegicus) were collected and examined. Based on the abundant original data, the present paper analyzed the infestation and distribution of chigger mites on this species of rodent. Before the present study, our research group made some ecological analyses of gamasid mites, fleas and sucking lice on $R$. norvegicus (Zuo \& Guo, 2011; Liu et al., 2020). Based on 431 Brown rats collected between 2003 and 2004 from a localized area in Yunnan Province of Southwest China, a previous study analyzed the species abundance distribution of ectoparasites on $R$. norvegicus, which involved four categories of ectoparasites - fleas, sucking lice, gamasid mites and chigger mites. In the study, 23 species of chigger mites were identified from $R$. norvegicus, which accounted for $48.94 \%$ of the total species of ectoparasites (23/47) (Guo et al., 2016). According to some "data mining" ideas and strategies, the present study took the advantage of the abundant original data to make a detailed analysis of chigger mites on $R$. norvegicus. This is an attempt to provide more valuable information about the relations of chiggers with the rat species.

\section{MATERIALS AND METHODS}

\section{Field investigation}

The original data came from a long-term field investigation in 33 counties of Yunnan Province, Southwest China between
2001 and 2015. Located in the southwest of China, Yunnan Province $\left(21^{\circ} 09^{\prime}-29^{\circ} 15^{\prime} \mathrm{N}, 97^{\circ} 32^{\prime}-106^{\circ} 12^{\prime} \mathrm{E}\right)$ is a vast geographical region $\left(390,000 \mathrm{~km}^{2}\right)$ with 129 counties (Zhan et al., 2013; Peng et al., 2016a). The 33 counties are as follows: Binchuan, Cangyuan (Lincang), Dali, Deqin, Fugong, Fuyuan, Gengma, Gongshan, Hekou, Jianchuan, Jinghong, Jinping, Lanping, Lianghe, Longchuan, Luliang, Lushui, Maguan, Menghai, Mengla, Mengzi, Ninger, Qiaojia, Qiubei, Ruili, Simao (Puer), Suijiang, Weixi, Wenshan, Xianggelila, Yongde, Yuanjiang and Yulong (Lijiang) (Figure 1).

Yunnan Province is a mountainous region with complex terrains and diverse climate. There are two types of landscapes in Yunnan, the mountainous landscapes and flatland landscapes. The plateaus with mountains form the typical mountainous landscapes, and the small plains and basins dotted among high mountains form the typical flatland landscapes. From the Northwest to the Southeast of Yunnan, the altitudes gradually decrease, forming different altitude gradients (He \& Zhang, 2006; Ding et al., 2020). The climate in the same season varies in different regions of Yunnan. Although it is still warm in the Southeast with low altitudes, it is getting cold in the Northwest with high altitudes (Xu, 1991; He et al., 2019). Considering the complex topography and diverse climate of Yunnan, the field investigations in the present study were mainly made in relatively warm and dry seasons without much flood (March to May and August to October). A few investigations were conducted in June and July in some high plateaus with high altitudes and low temperature. No investigation was made in cold winter seasons (November to February).

\section{Collection and identification of Brown rats and chigger mites}

The investigation was made in different geographical localities (investigation sites), different landscapes, altitudes and habitats (the indoor and outdoor habitats). In each investigation site, mousetraps were placed in different habitats to capture rodents and other small mammals (e.g., insectivores and tree shrews) in the evening and removed next morning (Huang et al., 2017; Guo et al., 2016). Each captured host animal was put into a white cloth bag and then brought to a temporary laboratory where the larvae of chigger mites (chiggers) were collected and stored in a labeled vial containing 70\% ethanol (Durden et al., 2004; Eslami et al., 2018). After the mite collection, the host animals were identified to species according to their morphological features (Kia et al., 2009; Huang et al., 2017). The Brown rat ( $R$. norvegicus) was selected as the target of the present study. The collected chiggers were mounted on glass slides in Hoyer's medium. Chiggers were identified to species under a Leica DM 3000 LED microscope using taxonomical keys (Vercammen-Grandjean \& Langston 1976; Wen, 1984; Li et al., 1997; Stekolnikov, 2013).

\section{General statistical analysis of chigger mites}

The constituent ratio $\left(C_{r}\right)$, prevalence $\left(P_{m}\right)$, mean abundance $(M A)$ and mean intensity $(M I)$ were used to analyze the infestation of each species of chigger mite on $R$. norvegicus (Bush et al., 1997; Zhan et al., 2013). The richness (S), ShannonWiener's diversity index $\left(H^{\prime}\right)$, Pielou's evenness $(E)$ and Simpson's dominance index $(D)$ were used to describe the mite community structure (Magurran, 1998; Peng et al., 2016b):

$$
C_{r}=\frac{N_{i}}{N} \times 100 \% ; \quad P_{m}=\frac{H_{i}}{H} \times 100 \% ; \quad M A=\frac{N_{i}}{H} ; \quad M I=\frac{N_{i}}{H_{i}} ;
$$

$$
S=\sum S_{i} ; \quad H^{\prime}=-\sum_{i=1}^{S}\left(\frac{N_{i}}{N}\right) \ln \left(\frac{N_{i}}{N}\right) ; \quad E=\frac{H^{\prime}}{\ln S} ; \quad D=\sum_{i=1}^{S}\left(\frac{N_{i}}{N}\right)^{2},
$$




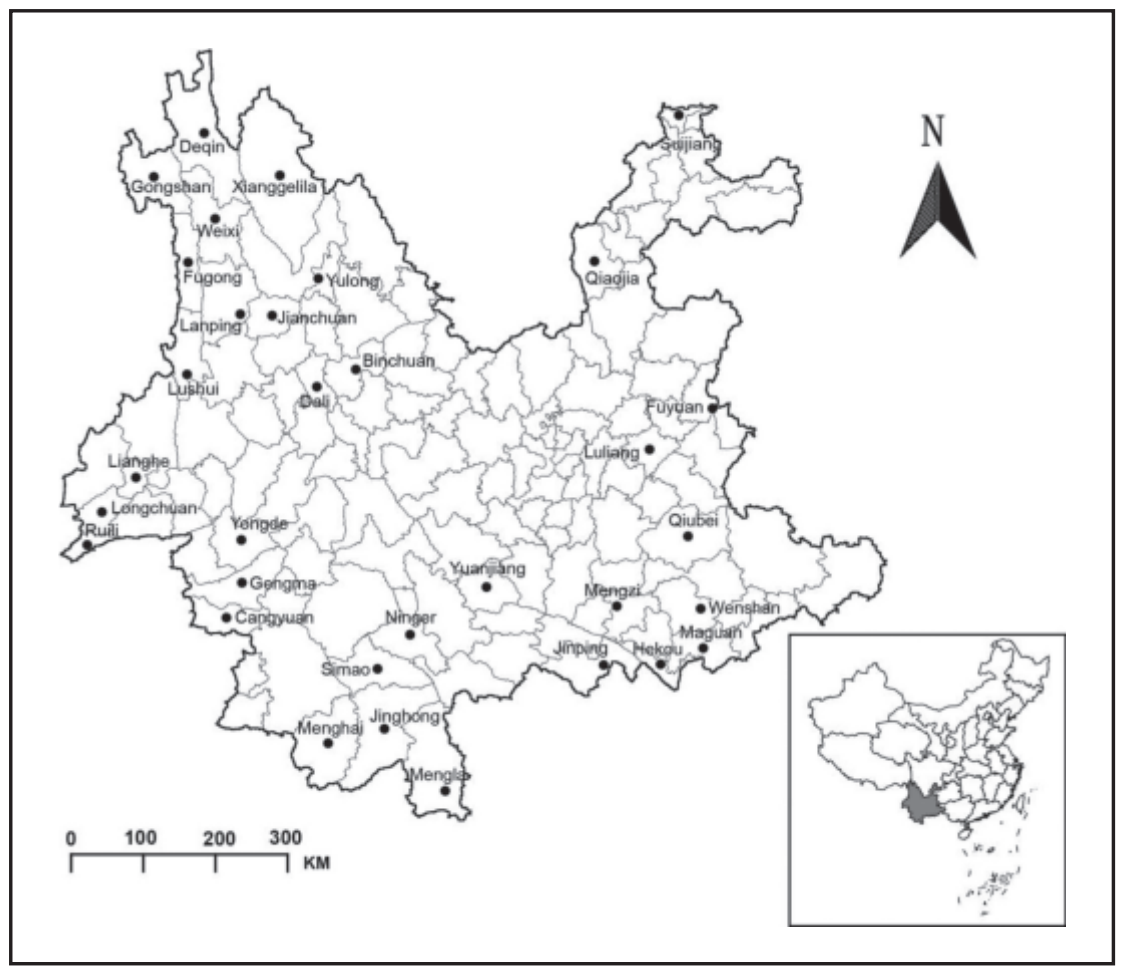

Figure 1. The 33 counties of Yunnan Province of Southwest China (2001-2015).

where $N_{i}$ is the number of a certain mite species $i, N$ - total number of all mites, $H$ - total number of examined host individuals, $H_{i}$ - number of infested host animals, and $S_{i}-$ species $i$.

\section{Analysis of spatial distribution pattern of chigger mites}

The dispersion coefficient $(C)$, patchiness index $\left(\mathrm{m}^{*} / \mathrm{m}\right)$, I-index $(I)$ and Cassie index $\left(C_{A}\right)$ were used to analyze the spatial distribution pattern of chigger mites among different individuals of $R$. norvegicus (Kuno, 1991; Saburova et al., 1995; Guo et al., 2006):

$$
C=\frac{\sigma^{2}}{m} ; \quad m * / m=\frac{m+I}{m} ; \quad I=C-1 ; \quad C_{A}=\frac{\sigma^{2}-m}{m^{2}},
$$

where $m, \sigma^{2}$ and $m^{*}$ represent the mean, variance and mean crowding of chigger mites on the host. The aggregated distribution is determined when calculated indices are beyond their boundary values: $C$ and $m * / m>1$, and $I$ and $C_{A}>0$ (Wang et al., 2019; Liu et al., 2020).

Species composition of chigger mites on male and female hosts Sorensen index $\left(C_{s s}\right)$ was used to compare the species compositions of chigger mites on male and female hosts, $R$. norvegicus (Peng et al., 2015; Liu et al., 2020):

$$
C_{s s}=\frac{2 C}{S_{m}+S_{f}}
$$

where $C$ is the number of chigger species on both sexes, $S_{m}-$ number of species on male hosts, and $S_{f}$ - number of species on female hosts.

\section{Species abundance distribution and species-plot relationship}

In a semi-logarithmic coordinate system, X-axis was labeled with log intervals based on $\log _{3} M$, which indicates the individuals of chigger mites, and $\mathrm{Y}$-axis was marked with arithmetic scales, which represents the mite species. As following formulae, Preston's lognormal model was used to fit the theoretical curve of species abundance distribution and the fitting goodness $\left(R^{2}\right)$ was calculated. The total mite species on $R$. norvegicus was then estimated (Preston, 1948; Baltanas, 1992; Peng et al., 2017):

$\hat{S}(R)=S_{0} e^{-\left[a\left(R-R_{0}\right)\right]^{2}}$ (Preston's lognormal distribution model);

$$
R^{2}=1-\frac{\sum_{R=0}^{m}[S(R)-\hat{S}(R)]^{2}}{\sum_{R=0}^{m}[S(R)-\bar{S}(R)]^{2}} ; \bar{S}(R)=\frac{1}{m} \sum_{R=0}^{m} S(R) ; S_{T}=\left(S_{0} \sqrt{\pi}\right) / \alpha
$$

where $\hat{S}(R)$ is the theoretical number of chigger species at $R$-th log interval, $S(R)$ the actual mite species at $R$-th log interval, $R_{0}$ the mode log interval, $S_{0}$ the mite species at $R_{0}$ log interval, $m$ the number of log intervals, $\bar{S}(R)$ the average species for each log interval, and $S_{T}$ the total expected mite species. The value of $\alpha$ was determined according to the best fitting goodness, $R^{2}$ (Guo et al., 2006; Peng et al., 2017).

In the study of species-plot (or sample) relationship, 1113 captured rats ( $R$. norvegicus) were randomly numbered and grouped. There were 50 rats in each group with the remaining 63 rats in the last group. In a rectangular coordinate system, the scatter plot and tendency curve of the species-sample relationship were made when $X$-axis was marked with the log-transformed rat individuals and $Y$ axis was labeled with the cumulative species of chigger mites (Zhang et al., 2007).

\section{RESULTS}

Collection and identification of chigger mites on Rattus norvegicus 1414 chigger mites were collected from 1113 Brown rats in 18 of 33 investigated counties. The overall infestation prevalence $\left(P_{m}\right)$, mean abundance $(M A)$ and mean intensity 
Ding et al. (2021), Tropical Biomedicine 38(1): 111-121

Table 1. The chigger mites found on the Brown rat (Rattus norvegicus) in Yunnan Province (2001-2015)

\begin{tabular}{|c|c|c|c|}
\hline Familiy and Subfamilies & Genera & Chigger species & Chigger individuals \\
\hline Familiy Trombiculidae & & 61 & 1414 \\
\hline \multirow[t]{9}{*}{ Subfamily Trombiculinae } & Leptotrombidium & 38 & 577 \\
\hline & Trombiculindus & 1 & 4 \\
\hline & Neotrombicula & 1 & 6 \\
\hline & Helenicula & 1 & 29 \\
\hline & Cheladonta & 1 & 8 \\
\hline & Ascoschoengastia & 4 & 329 \\
\hline & Walchiella & 1 & 25 \\
\hline & Herpetacarus & 4 & 36 \\
\hline & Euschoengastia & 1 & 3 \\
\hline \multirow[t]{2}{*}{ Subfamily Gahrliepiinae } & Walchia & 7 & 376 \\
\hline & Gahrliepia & 2 & 21 \\
\hline
\end{tabular}

Table 2. Infestations of Rattus norvegicus with four main species of chigger mites in Yunnan Province (2001-2015)

\begin{tabular}{|c|c|c|c|c|c|c|c|}
\hline \multirow{2}{*}{$\begin{array}{l}\text { Names of chigger } \\
\text { mite species }\end{array}$} & \multicolumn{2}{|c|}{ Number of rats } & \multicolumn{2}{|c|}{ Number of chiggers } & \multicolumn{3}{|c|}{ Infestations of rats with chigger mites } \\
\hline & Examined & Infested & Individuals & $C_{r}(\%)$ & $\begin{array}{c}\text { Prevalence } \\
\left(P_{m}\right)(\%)\end{array}$ & $\begin{array}{c}\text { Mean abundance } \\
(M A)\end{array}$ & $\begin{array}{c}\text { Mean intensity } \\
(M I)\end{array}$ \\
\hline W. ewingi & 1113 & 26 & 215 & 15.21 & 2.34 & 0.19 & 8.27 \\
\hline A. indica & 1113 & 3 & 147 & 10.40 & 0.27 & 0.13 & 49.00 \\
\hline W. koi & 1113 & 41 & 139 & 9.83 & 3.68 & 0.12 & 3.39 \\
\hline A. rattinorvegici & 1113 & 15 & 127 & 8.98 & 1.35 & 0.11 & 8.47 \\
\hline Each of other species & 1113 & $1-16$ & $1-88$ & $0.07-6.22$ & $0.09-1.44$ & $0-0.08$ & $1-17.33$ \\
\hline
\end{tabular}

$(M I)$ of the mites were $13.39 \%, 1.27$ mites/rat and 9.49 mites/ rat respectively. The mites were identified as comprising 61 species, 11 genera and 2 subfamilies (Trombiculinae and Gahrliepiinae) of the family Trombiculidae (Table 1 and the "Appendix" at the end of the text). The mites in the subfamily Trombiculinae accounted for $71.92 \%$ of the total (1017/1414, $\left.C_{r}=71.92 \%\right)$ and the mites of the genus Leptotrombidium accounted for $56.74 \%$ of the total Trombiculinae mites (577) 1017, $\left.C_{r}=56.74 \%\right)$. As shown in Table 2, the constituent ratios of four main mite species were higher $\left(C_{r}: 8.98 \%-15.21 \%\right)$ than of other species $\left(C_{r}: 0.07-6.22 \%\right.$ for each species). Of the four main mite species, Walchia koi had the highest prevalence $\left(P_{m}=3.68 \%\right)$ and $W$. ewingi had the highest mean abundance $(M A=0.19)$ with statistical significance $(P<0.05)$. The mean intensity of Ascoschoengastia indica $(M I=49)$ was higher than of the other three species with statistical significance $(P<0.05)$ (Table 2$)$. The chigger community on $R$. norvegicus consisted of 61 species $(S=61)$, and its diversity index $\left(H^{\prime}\right)$, evenness $(E)$ and dominance index $(D)$ were 3.13 , 0.76 and 0.0679 , respectively.

Spatial distribution pattern of chigger mites on Rattus norvegicus As showed in Table 3, the calculated values of four indices for four main species of chigger mites and all 61 species together were higher than their boundary values ( 1 or 0 ), and therefore chigger mites were determined to be of aggregated distribution among different individuals of $R$. norvegicus.

Infestations of rats with chigger mites in different habitats and landscapes

As shown in Table 4, the outdoor Brown rats harbored much more individuals and species of chigger mites than the indoor rats. The mean abundance $(M A=1.46)$ and mean intensity $(M I=12.53)$ of the mites in outdoors were also higher
Table 3. Analysis on spatial distribution patterns of chigger mites on Rattus norvegicus

\begin{tabular}{lcccc}
\hline Chigger species & $C$ & $C_{A}$ & $l$ & $m^{*} / m$ \\
\hline W. ewingi & 24.75 & 122.97 & 23.75 & 123.97 \\
A. indica & 99.66 & 747.03 & 98.66 & 748.03 \\
W. koi & 10.84 & 78.80 & 9.84 & 79.80 \\
A. rattinorvegici & 37.09 & 316.31 & 36.09 & 317.31 \\
All 61 species together & 36.46 & 27.91 & 35.46 & 28.91 \\
\hline
\end{tabular}

than those in indoors $(M A=0.89, M I=5.23)$ with statistical significance $(Z=-2.137, P<0.05 ; Z=-3.979, P<0.001)$. The prevalence in outdoors $\left(P_{m}=11.62 \%\right)$, however, was lower than that in indoors $\left(P_{m}=17.03 \%\right)\left(\chi^{2}=6.2, P<0.05\right)$.

The Brown rats in the mountainous landscapes harbored much more species of chigger mites ( 55 species) than in the flatland landscapes (26 species). All the infestation indices of the mites in the mountainous landscapes $\left(P_{m}=23.75 \%\right.$, $M A=2.98$ and $M I=12.56)$ were significantly higher than those in the flatland landscapes $\left(P_{m}=10.21 \%, M A=0.75\right.$ and $\left.M I=7.30\right)$ with $P<0.001$ (Table 4).

\section{Infestations of rats with chigger mites at different altitudes}

The 1113 Brown rats ( $R$. norvegicus) were captured in 18 of 33 investigated counties. Of the 18 counties where $R$. norvegicus rats were captured, there were chigger mites found on the rats in 11 counties and no chigger mite was found in the rest 7 counties. The altitudes in the 11 counties were very different, varying from 80 meters above sea level to 3300 meters. The overall infestations of $R$. norvegicus with chigger mites showed some differences in the 11 counties with different altitudes (Table 5). The linear correlation and 
Ding et al. (2021), Tropical Biomedicine 38(1): 111-121

Table 4. Overall infestations of Rattus norvegicus with chigger mites in different habitats and landscapes

\begin{tabular}{|c|c|c|c|c|c|c|c|}
\hline \multirow{2}{*}{ Habitats and landscapes } & \multicolumn{2}{|c|}{ Number of rats } & \multicolumn{2}{|c|}{ Number of chiggers } & \multicolumn{3}{|c|}{ Indices of infestation } \\
\hline & Examined & Infested & Species & Individuals & $\begin{array}{l}\text { Prevalence } \\
\left(P_{m}\right)(\%)\end{array}$ & $\begin{array}{c}\text { Mean abundance } \\
\text { (MA) }\end{array}$ & $\begin{array}{c}\text { Mean intensity } \\
(M I)\end{array}$ \\
\hline Indoor habitats & 364 & 62 & 9 & 324 & 17.03 & 0.89 & 5.23 \\
\hline Outdoor habitats & 749 & 87 & 60 & 1090 & 11.62 & 1.46 & 12.53 \\
\hline Flatland Iandscapes & 852 & 87 & 26 & 635 & 10.21 & 0.75 & 7.30 \\
\hline Mountainous landscapes & 261 & 62 & 55 & 779 & 23.75 & 2.98 & 12.56 \\
\hline Total & 1113 & 149 & 61 & 1414 & 13.39 & 1.27 & 9.49 \\
\hline
\end{tabular}

Table 5. Infestation indices of Brown rats (Rattus norvegicus) with chigger mites and different altitudes in the 11 counties where chigger mites were found on the rats

\begin{tabular}{|c|c|c|c|c|c|c|c|c|c|c|c|}
\hline \multirow{2}{*}{ No. } & \multirow{2}{*}{ Counties } & \multirow{2}{*}{$\begin{array}{l}\text { Altitudes } \\
\text { (meters) }\end{array}$} & \multicolumn{3}{|c|}{ Infestation indices } & \multirow{2}{*}{ No. } & \multirow{2}{*}{ Counties } & \multirow{2}{*}{$\begin{array}{l}\text { Altitudes } \\
\text { (meters) }\end{array}$} & \multicolumn{3}{|c|}{ Infestation indices } \\
\hline & & & $P_{m}(\%)$ & $M A$ & MI & & & & $P_{m}(\%)$ & $M A$ & $M I$ \\
\hline 1 & Hekou & 80 & 20.00 & 5.80 & 29.00 & 7 & Dali & 2100 & 12.27 & 1.47 & 12.00 \\
\hline 2 & Jinghong & 584 & 100.00 & 125.00 & 125.00 & 8 & Yulong & 2150 & 10.00 & 0.20 & 2.00 \\
\hline 3 & Mengzi & 1300 & 26.32 & 2.28 & 8.65 & 9 & Luliang & 2178 & 14.48 & 0.50 & 3.48 \\
\hline 4 & Fuyuan & 1336 & 6.17 & 0.28 & 4.60 & 10 & Jianchuan & 2210 & 3.39 & 0.08 & 2.50 \\
\hline 5 & Menghai & 1450 & 66.67 & 7.67 & 11.50 & 11 & Weixi & 3300 & 18.97 & 2.38 & 12.55 \\
\hline 6 & Maguan & 1510 & 50.00 & 3.17 & 6.33 & Total & - & - & 13.39 & 1.27 & 9.49 \\
\hline
\end{tabular}

Table 6. Linear correlation and regression analysis between infestation indices and altitudes in the 11 counties where chigger mites were found on $R$. norvegicus

\begin{tabular}{lcccc}
\hline Infestation indices & $R$ & $R^{2}$ & $F$ & $P$ \\
\hline Prevalence $\left(P_{m}\right)$ & 0.453 & 0.205 & 2.322 & 0.162 \\
Mean abundance $(M A)$ & 0.435 & 0.189 & 2.097 & 0.181 \\
Mean intensity $(M I)$ & 0.503 & 0.253 & 3.045 & 0.115 \\
\hline
\end{tabular}

regression analysis was used to compare the relationship between the infestation indices (prevalence- $P_{m}$, mean abundance-MA and mean intensity- $M I$ ) and the different altitudes in 11 counties where chigger mites were collected. The results showed that all the correlation coefficients $(R)$ between three infestation indices $\left(P_{m}, M A\right.$ and $\left.M I\right)$ and different altitudes were of no statistical significance $(P>0.05)$ (Table 6).

\section{Infestations of hosts of different sexes and ages with chiggers} The species similarity of chigger mites on male and female Brown rats was estimated by Sorensen index $\left(C_{s s}\right)$, and the same mite species on the male and female rats accounted for $64.44 \%\left(C_{s s}=64.44 \%\right)$. The community statistics $\left(S, H^{\prime}, E\right.$ and $D)$ showed some differences in the infestation of different sexes and ages (Table 7). The male rats harbored more species and individuals of chigger mites than the females. The overall mite infestations on the male rats $\left(P_{m}=14.65\right.$, $M A=1.49$ and $M I=10.16)$ were higher than those on the females $\left(P_{m}=11.98, M A=1.03\right.$ and $\left.M I=8.57\right)$, but not statistically insignificant $(P>0.05)$. The adult rats harbored more mite species and individuals than the juveniles (Table 7), but the overall infestations with the mites were not significantly different on different ages of the rats $(P>0.05)$.

Species abundance distribution and species-plot relationship Of the 1414 individuals of chigger mites collected from $R$. norvegicus, most belonged to rare species represented by only one or 2-4 individuals (Table 8). By using Preston's model, the species abundance distribution of the mite community was fitted as $\hat{S}(R)=15 e^{-[0.31(R-1)]^{2}}\left(\alpha=0.31, R^{2}=0.95\right)$, and the theoretical curve showed a parabolic tendency (Figure 2). Within the community, a few dominant species of the mites were relatively abundant (Table 8 and Figure 2). On the basis of the curve fitting, the total mite species on the rat was estimated to be 86 species.

The tendency curve of the species-plot relationship showed that the number of chigger species rapidly increased with the increase of sampled rat individuals in the beginning. When the sampled rats were accumulated to 250 individuals, the number of mite species rapidly reached 41 . After that, the increasing speed of the mite species number became gradually slow, but still kept increasing (Figure 3 ).

Table 7. Overall infestations and community structure of chigger mites on different sexes and ages of Rattus norvegicus

\begin{tabular}{|c|c|c|c|c|c|c|c|c|c|}
\hline \multirow{2}{*}{\multicolumn{2}{|c|}{ R. norvegicus $(\mathrm{n}=1113)$}} & \multicolumn{4}{|c|}{ Overall infestations with chigger mites } & \multicolumn{4}{|c|}{ Community structure } \\
\hline & & Individuals & $P_{m}(\%)$ & MA & MI & $S$ & $H^{\prime}$ & $E$ & $D$ \\
\hline \multirow[t]{2}{*}{ Sexes } & Male (587) & 874 & 14.65 & 1.49 & 10.16 & 49 & 2.922 & 0.751 & 0.088 \\
\hline & Female (526) & 540 & 11.98 & 1.03 & 8.57 & 41 & 2.916 & 0.785 & 0.081 \\
\hline \multirow[t]{2}{*}{ Ages } & Juvenile (424) & 484 & 14.15 & 1.14 & 8.07 & 36 & 2.749 & 0.767 & 0.110 \\
\hline & Adult (689) & 930 & 12.92 & 1.35 & 10.45 & 50 & 3.018 & 0.772 & 0.073 \\
\hline
\end{tabular}


Ding et al. (2021), Tropical Biomedicine 38(1): 111-121

Table 8. Analysis on species abundance distribution of chigger mites on Rattus norvegicus based on Preston's model

\begin{tabular}{cccc}
\hline $\begin{array}{c}\text { Log intervals } \\
\text { (A) }\end{array}$ & $\begin{array}{c}\text { Individual ranges in each } \\
\text { log interval (B) }\end{array}$ & $\begin{array}{c}\text { Midpoint values of each } \\
\text { individual range (C) }\end{array}$ & $\begin{array}{c}\text { Actual chigger mites } \\
\text { species }\end{array}$ \\
\hline 0 & $0-1$ & 1 & $\begin{array}{c}\text { Theoretical chigger } \\
\text { mites species }\end{array}$ \\
1 & $2-4$ & 3 & 13 \\
2 & $5-13$ & 9 & 13.63 \\
3 & $14-40$ & 27 & 13 \\
4 & $41-121$ & 81 & 6 \\
5 & $122-364$ & 243 & 6.32 \\
\hline
\end{tabular}

Note: $\mathrm{C}$ is the midpoint of $\mathrm{B}, 3^{\mathrm{A}}=\mathrm{C}, \log _{3} \mathrm{C}=\mathrm{A}, \alpha=0.31, R^{2}=0.95$.

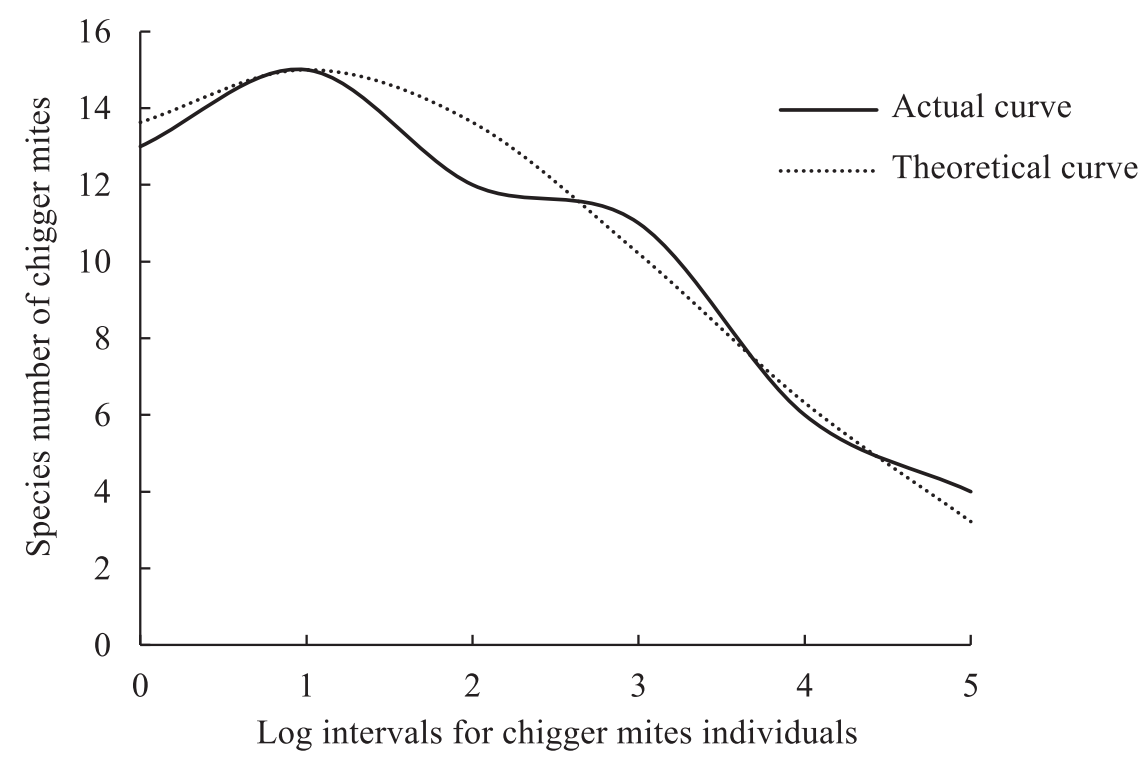

Figure 2. Theoretical curve fitting for species abundance of chigger mites on Rattus norvegicus based on Preston's model.

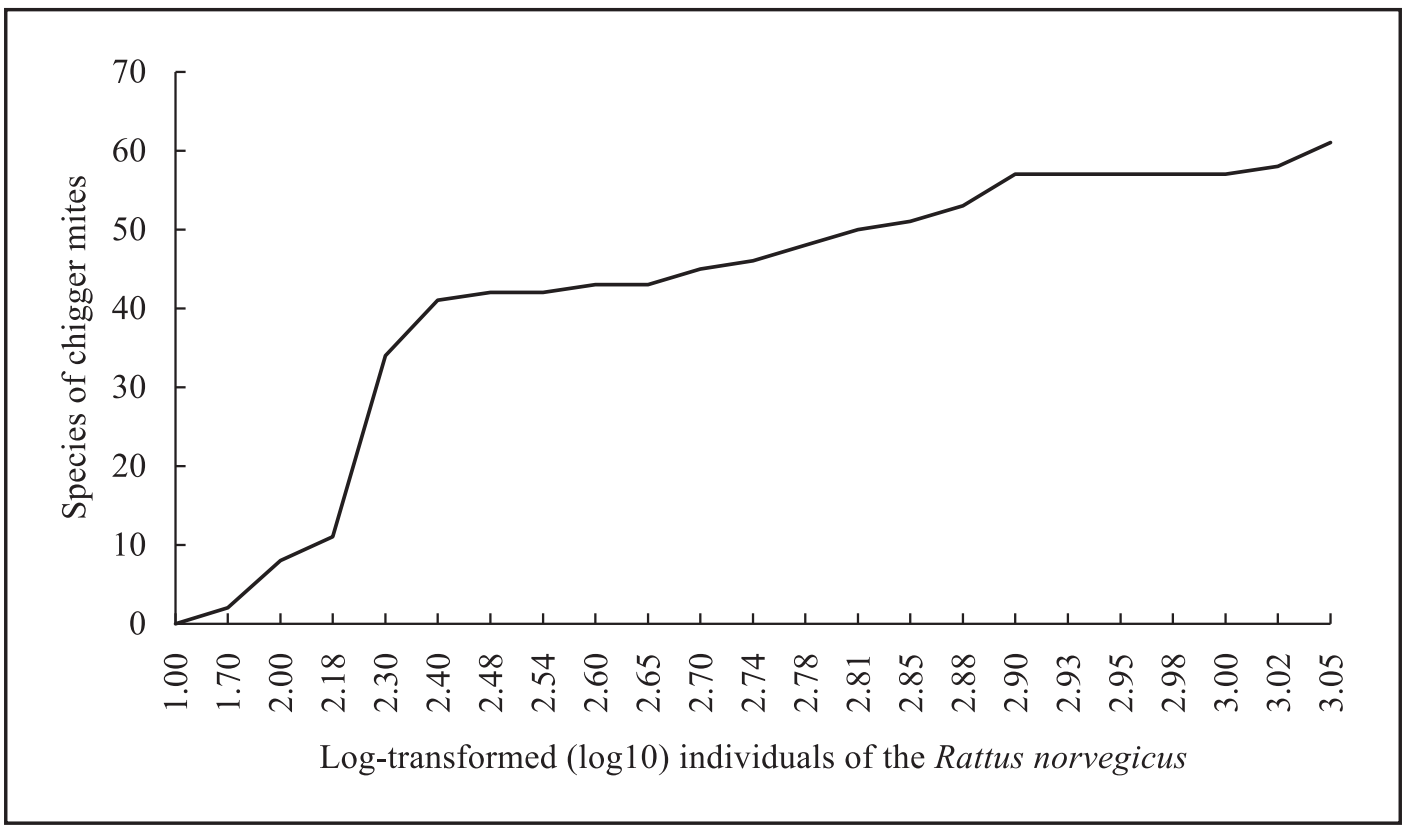

Figure 3. Species-plot relation of chigger mites on Rattus norvegicus. 


\section{DISCUSSION}

\section{Infestation of Rattus norvegicus with chigger mites}

The Brown rat in Yunnan Province harbored 61 species of chigger mites on its body surface, which exceed the total recorded species of chigger mites in some other provinces of China, for example 37 species in Qinghai Province (Yang et al., 2014) and 24 species in Shandong Province (Xue et al., 2004). In comparison with the previous study in a localized area of Yunnan, in which 23 species of chigger mites were identified from $R$. norvegicus (Guo et al., 2016), 38 more chigger species were found on the rat in the present study $(61-23=38)$. The 61 species of chigger mites were listed in "Appendix: Name list of chigger species identified from Rattus norvegicus at the end of the text, and the 38 newly recorded species were marked with "\#". Chigger mites usually have a wide range of hosts with low host specificity. Through cross infestation, the same species of chigger mites can infest different host species at the same time and the same host species can harbor different mite species as well (Guo et al., 2016; Peng et al., 2017). The high number of chigger species on $R$. norvegicus may be caused by the extensiveness of field investigations in 33 counties of Yunnan with large host samples (1113 Brown rats). In addition, the species richness of chigger mites on $R$. norvegicus may be also related to the diversity of natural conditions in Yunnan Province where more than $50 \%$ of animal and plant species of the whole China have been recorded with a very high biodiversity (Young \& Wang, 1989; Zhan et al., 2013).

It has been proved that the six species of chigger mites are the main vectors of scrub typhus in China and they are Leptotrombidium scutellare, L. deliense, L. wenense or L. kaohuense, L. sialkotense or L. jishoum, L. rubellum and L. insulare (Stekolnikov, 2013; Peng et al., 2016a; Luo \& Yin, 2019; Lv et al., 2020). Of the six main vectors, four species were identified from Rattus norvegicus in the present study, but they were not the dominant species on the rat. The constituent ratios $\left(C_{r}\right)$ of the four vector species were $6.22 \%(88 / 1414)$ for $L$. scutellare, $2.12 \%$ (30/1414) for $L$. wenense, $0.42 \%(6 / 1414)$ for $L$. insulare and $0.07 \%$ (1/1414) for L. deliense, respectively. In Appendix: Name list of chigger species identified from Rattus norvegicusat the end of the text, the main vectors and the subordinate or potential vectors were marked with "**" and "*".

Although $R$. norvegicus harbored a lot of chigger species, the infestation load was not heavy (in total, only 1414 individuals of chigger mites were collected from 1113 rats). In comparison with some other species of rodents, the overall infestation of $R$. norvegicus with chigger mites was relatively low $\left(P_{m}=13.39 \%, M A=1.27 \mathrm{mites} / \mathrm{rat}\right.$ and $M I=9.49$ mites/rat). Previously, chigger mites on the large oriental vole (Eothenomys miletus) were investigated across three provinces (Sichuan, Guizhou and Yunnan) of Southwest China, and 175 species and 49,850 individuals of chigger mites were collected from 2463 vole hosts (Peng et al., 2016c). The overall mean abundance (MA) on E. miletus reached 20.24 mites/vole $(49,850 / 2463)$, which is much higher than that (MA=1.27 mites/rat) on $R$. norvegicus in the present study. Based on the materials from 431 Brown rats, four categories of ectoparasites (fleas, sucking lice, gamasid mites and chigger mites) were reported from a study area in Yunnan of Southwest China. Of 8040 ectoparasites collected from that host species, there were only 345 chigger mites (belonging to 23 species) with a low infestation load $\left(P_{m}=7.4 \%, M A=0.8\right.$ mites/rat and $M I=10.8$ mites $/ \mathrm{rat})$, which is similar to the infestation load observed in the present study (Guo et al., 2016).
The constituent ratios for the four main species of chigger mites on $R$. norvegicus were rather low $\left(C_{r}: 8.98 \%-15.21 \%\right)$, without an obviously dominant mite species (Table 2 ). The dominance index of chigger mite community on $R$. norvegicus also showed a very low value $(D=0.0679)$, which indicates that the dominance of the main mite species is not prominent. The results suggest that most species of chigger mites are only occasional parasites of $R$. norvegicus. The dominant species of chigger mites on $R$. norvegicus recorded by Guo et al. (2016) were A. rattinorvegici, Leptotrombidium bengbuense and L. akamushi, which are different from the four most abundant species of the present study ( $W$. ewingi, $A$. indica, W. koi and A. rattinorvegici). This difference implies the low host specificity of the mites without a stable hostparasite connection between $R$. norvegicus and specific chigger mites.

Spatial distribution pattern of chigger mites on Rattus norvegicus The four indices $\left(C, I, C_{A}\right.$ and $\left.m^{*} / m\right)$ used in the present study are simple and practicable ways to determine the spatial distribution patterns of populations (Kuno, 1991; Wang et al., 2019; Liu et al., 2020). The results showed that chigger mites were of aggregated distribution among different individuals of $R$. norvegicus (Table 3 ), which is commonly seen in some other ectoparasites (Zuo \& Guo, 2011; Huang et al., 2013). The aggregated distribution pattern revealed that some rats harbored few or no chigger mites, while some other rats harbored abundant mites, forming mite clusters. The aggregated distribution pattern of chigger mites may be beneficial to their reproduction, mating and survival (Kennedy, 1976; Rohde, 1993; Huang et al., 2013).

Infestation with chigger mites in different habitats, landscapes and altitude gradients

In comparison with the indoor rats, the outdoor rats had a heavier infestation load of chigger mites with much more mite species and individuals and higher $M A$ and $M I$ even though $P_{m}$ was an exception (Table 4 ). Most chigger mites have a preference to breed in humid environments (Clopton \& Gold, 1993; Li et al., 2002). A relatively high humidity outdoors may result in heavier infestations on the outdoor rats than the indoor rats (Niu et al., 2006; Li et al., 2017). In addition, the outdoor habitats are more complex with different types of farmlands, scrubs and woodlands than the indoor habitats (houses, barns, stalls and stables) in Yunnan Province. There are more rodent species in the outdoors than in the indoors and this also allows the outdoor rats to harbor more mite species via cross infestation (Niu et al., 2006; Zhan et al., 2013).

Different landscapes also greatly influenced the infestation of $R$. norvegicus with chigger mites. Brown rats in the mountainous landscapes harbored more individuals and species of chigger mites with significantly higher infestations $\left(P_{m}, M A\right.$ and $\left.M I\right)$ than in the flatland landscapes (Table 4), and this may be related to the relatively high biodiversity, complex vegetation and environments in mountainous landscapes of Yunnan Province (Pongsiri et al., 2009; Zhan et al., 2013; Peng et al., 2018). In the present study, the altitudes were very different in the 11 counties where chigger mites were found on $R$. norvegicus rats. The different altitudes in the 11 counties were used in the linear correlation and regression analysis between the infestation indices of $R$. norvegicus with chigger mites and the altitudes. Although the overall infestations showed some differences in the 11 counties with different altitudes (Table 5 ), the correlation coefficients $(R)$ between the infestation indices $\left(P_{m}, M A\right.$ and 
$M I)$ and different altitudes were of no statistical significance $(P>0.05)$. The result of the present study seems difficult to illustrate the influence of altitudes on the infestations of $R$. norvegicus with chigger mites, and more researches may be needed in the future studies.

Infestations of different sexes and ages of hosts with chigger mites The result showed that the chigger species found both on the male and female Brown rats accounted for $64.44 \%$ $\left(C_{s s}=64.44 \%\right)$, and this indicates that there are $35.56 \%$ of mite species different between two sexes of the rat hosts. Although the higher overall infestations $\left(P_{m}, M A\right.$ and $\left.M I\right)$ of the male rats than the females were of no statistical significance $(P>0.05)$, the male rats did harbor more species and individuals of chigger mites than the females (Table 7), and this reflects the sexes bias in the infestations with the mites. The sex bias is common in endoparasite and ectoparasite infestations. Different mating behaviors and different SSD (sexual size dimorphism) of male rats may affect their immunity that made them more vulnerable to parasites (Folstad \& Karter, 1992; Moller et al., 1999). Male rats are more likely to be infested than female rats, because of larger size and wider range of activities (Peng et al., 2015). Larger hosts are more susceptible to parasites because they can provide more space and niche diversity for them (Poulin, 1997).

The adult Brown rats harbored more species and individuals of the mites with higher $M A$ and $M I$, and this seems to reflect a tendency of the mite infestations in different ages of the rats. However, the overall infestations with the mites were not statistically different for rats of different ages $(P>0.05)$ (Table 7$)$, and more studies are still needed.

\section{Species abundance distribution and species-plot relationship of chigger mites}

The species abundance distribution is to describe the relationship between the number of individuals in a certain community and the species they belong to. Preston's lognormal model is a useful way to fit the theoretical curve of species abundance distributions (Preston, 1948; McGill et al., 2007; Peng et al., 2017). On the basis of fitting the theoretical curve, the total species within a community can be roughly estimated by using the formula (Baltanas, 1992; Peng et al., 2017). In the present study, all the species of chigger mites on Brown rats form a community of the mites. The species abundance distribution of the chigger mite community on $R$. norvegicus was successfully fitted by Preston's model with a high value of fitting goodness $\left(R^{2}=0.95\right)$ (Figure 2), and this indicates that the species abundance distribution of the mite community conforms to the lognormal distribution (Guo et al., 2016; Liu et al., 2020). On the basis of the above fitting, the total mite species on $R$. norvegicus was estimated to be 86 species, and this implies that there are 25 rare mite species missed in the sampling investigation. Some rare species are unavoidable to be missed in the sampling process because some of them are too rare to be collected (Baltanas, 1992; Chao \& Shen, 2003; Peng et al., 2017).

In the present study, the species-plot relationship is to describe the relationship between the sampling plots (the individuals of Brown rats) and the accumulated species of chigger mites. In theory, the species-plot curve will ultimately reach a "platform stage" with no more species increased when the sampling plots are large enough (Arrhenius, 1923; Peng et al., 2016c; Liu et al., 2020). When the "platform stage" appears, the minimum sampling plots can be determined according to the midpoint of the curve (Peng et al., 2016c; Liu et al., 2020). The result showed that the accumulated mite species rapidly increased in the beginning and then the increasing speed gradually became slow, but still kept goingup (Figure 3 ). The curve tendency of the species-plot relationship indicates that $R$. norvegicus have a great potential to harbor many species of chigger mites, and more species of the mites would be collected if more rats are sampled. Since the "platform stage" didn't appear on the curve, the minimum sampling plots (the rat individuals) can't be determined. If we expect to get a stable "platform stage" on the curve and then determine the minimum plots, more sampling rat individuals are needed.

\section{ACKNOWLEDGEMENTS}

We would like to express our sincere thanks to following people who made lots of contributions in the field investigation and laboratory work: Qiao-Hua Wang, Yong Zhang, Cong-Hua Gao, Nan Zhao, Jian-Chang He, Guo-Li Li, Yan-Liu LiXue-Song He, De-Cai Ouyang, Shuang-Lin Wang, some colleagues and college students. The project was supported by the National Natural Science Foundation of China (No. 81672055; 81960380) to Xian-Guo Guo, and the Innovation Team of Vector Biology, Dali University (No. ZKLX2019104).

\section{Conflict of interest}

No conflict of interest exists in the submission of this manuscript, and the manuscript is approved by all authors for publication.

\section{Supplemental statement}

The sampling of Brown rats ( $R$. norvegicus) was officially permitted by the local authority of wildlife service in Dali Prefecture, Yunnan Province, China. The use of animals (Brown rats) for research was also officially approved the Institute of Pathogens and Vectors, Dali University.

\section{REFERENCES}

Alonso, R., Ruiz, M., Lovera, R., Montes De Oca, D.P., Cavia, R. \& Sánchez, J.P. (2019). Norway rat (Rattus norvegicus) ectoparasites in livestock production systems from central Argentina: influencing factors on parasitism. Acta Tropica 203: 105299. https://doi.org/10.1016/j.actatropica.2019. 105299

Arrhenius, O. (1923). On the relation between species and area: A reply. Ecology 4: 90-91. https://doi.org/10.2307/ 1929283

Axman, W.R. \& Brummer, J.J. (2003). Chigger mite infestation. Journal of the American Podiatric Medical Association 93: 399401. https://doi.org/10.7547/87507315-93-5-399

Baltanas, A. (1992). On the use of some methods for the estimation of species richness. Oikos 65: 484-492. https://doi.org/10.2307/3545566

Bush, A.O., Lafferty, K.D., Lotz, J.M. \& Shostak, A.W. (1997). Parasitology meets ecology on its own terms: Margolis et al., revisited. The Journal of Parasitology 83: 575-583. https://doi.org/10.2307/3284227

Candasamy, S., Ayyanar, E., Paily, K., Karthikeyan, P.A., Sundararajan, A. \& Purushothaman, J. (2016). Abundance \& distribution of Trombiculid mites \& Orientia tsutsugamushi, the vectors \& pathogen of scrub typhus in rodents \& shrews collected from Puducherry \& Tamil Nadu, India. Indian Journal of Medical Research 144: 893-900. https:// doi.org/10.4103/ijmr.IJMR_1390_15 
Castillo, D.S.C. \& Paller, V.G.V. (2018). Occurrence of Angiostrongylus cantonensis in rodents from the rice granary of the Philippines and associated risk factors for zoonotic transmission. Journal of Parasitic Diseases 42: 350-356. https://doi.org/10.1007/s12639-018-1005-z

Chao, A. \& Shen, T.J. (2003). Non-parametric estimation of Shannon's index of diversity when there are unseen species in sample. Environmental and Ecological Statistics 10: 429-443. https://doi.org/10.1023/A:1026096204727

Clopton, R. \& Gold, R. (1993). Distribution and seasonal and diurnal activity patterns of Eutrombicula alfreddugesi (Acari: Trombiculidae) in a forest edge ecosystem. Journal of Medical Entomology 30: 47-53. https://doi.org/10.1093/ jmedent $/ 30.1 .47$

Ding, F., Jiang, W.L., Guo, X.G., Fan, R., Mao, K.Y., Zhao, C.F., Zhang, Z.W., Qian, T.J. \& Yang Z.H. (2020). A preliminary report on Walchia micropelta in Yunnan Province. Sichuan Journal of Zoology 39: 555-562.

Duan, H.S., Yang, Z.Q., Xu, G.Q., Zhou, S.L., Wen, X.M., Pan, X.X. \& Liu, Y.R. (2009). Trombiculid mite distribution in Hubei Province and zoogeographical demarcation of the Province. Journal of Pathogen Biology 4: 687-688.

Durden, L.A., Ellis, B.A., Banks, C.W., Crowe, J.D. \& Oliver, J.H (2004). Ectoparasites of gray squirrels in two different habitats and screening of selected ectoparasites for Bartonellae. Journal of Parasitology 90: 485-489. https://doi. org/10.1645/GE-3299

Eslami, A., Yousefi, A. \& Dowling, A.P.G. (2018). Prevalence of ectoparasites in black rat (Rattus rattus) from Mangrove forests of Qeshm Island, Iran. Comparative Clinical Pathology 27: 1583-1586. https://doi.org/10.1007/s00580-018-2777-3

Feng, A.Y.T. \& Himsworth, C.G. (2014). The secret life of the city rat: a review of the ecology of urban Norway and black rats (Rattus norvegicus and Rattus rattus). Urban Ecosystems 17: 149-162. https://doi.org/10.1007/s11252-013-0305-4

Folstad, I. \& Karter, A.J. (1992). Parasites, bright males, and the immunocompetence handicap. American Naturalist 139: 603-622. https://doi.org/10.1086/285346

Guo, X.G., Dong, W.G., Men, X.Y., Qian, T.J., Wu, D., Ren, T.G., Qin, F., Song, W.Y., Yang, Z.H. \& Fletcher, Q.E. (2016). Species abundance distribution of ectoparasites on Norway rats (Rattus norvegicus) from a localized area in Southwest China. Journal of Arthropod-Borne Diseases 10: 192-200.

Guo, X.G., Qian, T.J., Meng, X.Y., Dong, W.G., Shi, W.X. \& Wu, D. (2006). Preliminary analysis of chigger communities associated with house rats (Rattus flavipectus) from six counties in Yunnan, China. Systematic and Applied Acarology 11: 13-21. https://doi.org/10.11158/saa.11.1.2

He, Y.L., Xiong, Q.L., Yu, L., Qu, X.X. \& Yan, W.B. (2019). Adaptability of vegetation ecosystem to climate change based on the NDVI in Yunnan Province, China. Ecological Science 38: 165-172.

He, Y.L. \& Zhang Y.P. (2006). A preliminary study on the spatialtemporal pattern of NPP in Yunnan Province. Mountain Research 24: 193-201.

Huang, L.Q., Guo, X.G., Speakman, J.R. \& Dong, W.G. (2013). Analysis of gamasid mites (Acari: Mesostigmata) associated with the Asian house rat, Rattus tanezumi (Rodentia: Muridae) in Yunnan Province, Southwest China. Parasitology Research 112: 1967-1972. https://doi.org/ 10.1007/s00436-013-3354-y

Huang, X.D., Cheng, P., Zhao, Y.Q., Li, W.J., Zhao, J.X., Liu, H.M., Kou, J.X. \& Gong, M.Q. (2017). Chigger mite (Acari: Trombiculidae) survey of rodents in Shandong Province, northern China. Korean Journal of Parasitology 55: 555-559. https://doi.org/10.3347/kjp.2017.55.5.555

Kennedy, C.R. (1976). Ecological aspects of parasitology. Amsterdam: North Holland Publish, pp. 1-474.
Kia, E.B., Moghddas-Sani, H., Hassanpoor, H., Vatandoost, H., Zahabiun, F., Akhavan, A.A., Hanafi-Bojd, A.A. \& Telmadarraiy, Z. (2009). Ectoparasites of rodents captured in Bandar Abbas, Southern Iran. Iranian Journal of Arthropod Borne Diseases 3: 44-49.

Kuno, E. (1991). Sampling and analysis of insect populations. Annual Review of Entomology 36: 285-304. https://doi.org/ 10.1146/annurev.en.36.010191.001441

Lee, I.Y., Song, H.J., Choi, Y.J., Shin, S.H. \& Jang, W.J. (2014). Larval chigger mites collected from small mammals in 3 provinces, Korea. Korean Journal of Parasitology 52: 225-229. https://doi.org/10.3347/kjp.2014.52.2.225

Luo, Y. \& Yin, J. (2019) Progress in research of Orientia tsutsugamushi and its host and vector. Disease Surveillance 34: 920-923. https://doi.org/10.3784/j.issn.1003-9961.2019. 10.013

Li, G.C., Li, X.Y., Liu, J., Liu, H.J., Liu, J.L., Li, D.M., Lu, L., Shi, Q., Fu, X.P. \& Liu, Q.Y. (2017). Investigation of chigger mites and infection of Orientia tsutsugamushi in small mammals in Qing2an County. Chinese Journal of Vector Biology and Control 28: 1-3, 15.

Li, J.C., Wang, D.Q. \& Chen, X.B. (1997). Trombiculid mites of China (studies on vector and pathogen of tsutsugamushi disease). Guangzhou: Guangdong Science and Technology Publishing House, pp. 1-570.

Li, J.C., Zhen, X.Y., Xi, Z.Y., Ni, H., Zhang, H.H. \& Chen, C.F. (2002). Basic studies on trombiculid mites and vector chiggers mites in the transmission of tsutsugamushi disease for 45 years. Journal of Sun Yat-sen University (Medical Sciences) 23: 1-9.

Liu, D.Y., Liu, J., Liu, B.Y., Liu, Y.Y., Xiong, H.R., Hou, W. \& Yang, Z.Q. (2017). Phylogenetic analysis based on mitochondrial DNA sequences of wild rats, and the relationship with Seoul virus infection in Hubei, China. Virologica Sinica 32: 235-244. https://doi.org/10.1007/s12250-016-3940-0

Liu, Z., Guo, X.G., Fan, R., Zhao, C.F., Mao, K.Y., Huang, Z.W. \& Zhao, Y. (2020). Ecological analysis of gamasid mites on the body surface of Norway rats (Rattus norvegicus) in Yunnan Province, Southwest China. Biologia 75: 1325-1336. https://doi.org/10.2478/s11756-019-00383-z

Lv, Y., Guo, X.G. \& Jin, D.C. (2018). Research progress on Leptotrombidium deliense. Korean Journal of Parasitology 56: 313-324. https://doi.org/10.3347/kjp.2018.56.4.313

Lv, Y., Guo, X.G., Jin, D.C., Song, W.Y., Fan, R., Zhao, C.F., Zhang, Z.W., Mao, K.Y., Zou, Y.J. \& Yang, Z.H. (2020). Relative abundance of a vector of scrub typhus, Leptotrombidium sialkotense, in Southern Yunnan Province, China. Korean Journal of Parasitology 58: 153-159. https://doi.org/10.3347/ kjp.2020.58.2.153

Magurran, A.E. (1998). Measuring richness and evenness. Trends in Ecology and Evolution 13: 165-166. https://doi.org/ 10.1016/S0169-5347(97)01290-1

McGill, B.J., Etienne, R.S., Gray, J.S., Alonso, D., Anderson, M.J., Benecha, H.K., Dornelas, M., Enquist, B.J., Green, J.L., He, F., Hurlbert, A.H., Magurran, A.E., Marquet, P.A., Maurer, B.A., Ostling, A., Soykan, C.U., Ugland, K.I. \& White, E.P. (2007). Species abundance distributions: moving beyond single prediction theories to integration within an ecological framework. Ecology Letters 10: 995-1015. https:// doi.org/10.1111/j.1461-0248.2007.01094.x

Moller, A.P., Christe, P. \& Lux, E. (1999). Parasitism, host immune function, and sexual selection. Quarterly Reviews of Biology 74: 3-30. https://doi.org/10.1086/392949

Niu, A.Q., Guo, X.G. \& Bao, H.E. (2006). Studies on community diversity of small mammals and their ectoparasitic chigger mites from the surrounding areas of Erhai Lake in Dali of the Yunnan. Journal of Medical Pest Control 22: 81-84. 
Peng, P.Y., Guo, X.G., Jin, D.C., Dong, W.G., Qian, T.J., Qin, F. \& Yang, Z.H. (2017). Species abundance distribution and ecological niches of chigger mites on small mammals in Yunnan Province, Southwest China. Biologia 72: 1031-1040. https://doi.org/10.1515/biolog-2017-0119

Peng, P.Y., Guo, X.G., Jin, D.C., Dong, W.G., Qian, T.J., Qin, F., Yang, Z.H. \& Fan, R. (2018). Landscapes with different biodiversity influence distribution of small mammals and their ectoparasitic chigger mites: a comparative study from Southwest China. PLoS One 13: e0189987. https:// doi.org/10.1371/journal.pone.0189987

Peng, P.Y., Guo, X.G., Ren, T.G., Dong, W.G. \& Song, W.Y. (2016a). An updated distribution and hosts: trombiculid mites (Acari: Trombidiformes) associated with small mammals in Yunnan Province, Southwest China. Parasitology Research 115: 1923-1938. https://doi.org/10.1007/s00436-016-4934-4

Peng, P.Y., Guo, X.G., Ren, T.G., Song, W.Y., Dong, W.G. \& Fan, R. (2016b). Species diversity of ectoparasitic chigger mites (Acari: Prostigmata) on small mammals in Yunnan Province, China. Parasitology Research 115: 3605-3618. https:// doi.org/10.1007/s00436-016-5127-x

Peng, P.Y., Guo, X.G., Song, W.Y., Hou, P., Zou, Y.J. \& Fan, R. (2016c). Ectoparasitic chigger mites on large oriental vole (Eothenomys miletus) across Southwest, China. Parasitology Research 115: 623-632. https://doi.org/10.1007/s00436-015-4780-9

Peng, P.Y., Guo, X.G., Song, W.Y., Hou, P., Zou, Y.J., Fan, R. \& He, X.S. (2015). Analysis of ectoparasites (chigger mites, gamasid mites, fleas and sucking lice) of the Yunnan red-backed vole (Eothenomys miletus) sampled throughout its range in Southwest China. Medical and Veterinary Entomology 29: 403-415. https://doi.org/10.1111/mve.12134

Pongsiri, M.J., Roman, J., Ezenwa, V.O., Goldberg, T.L., Koren, H.S., Newbold, S.C., Ostfeld, R.S., Pattanayak, S.K. \& Salkeld, D.J. (2009). Biodiversity loss affects global disease ecology. BioScience 59: 945-954. https://doi.org/10.1525/bio.2009. 59.11.6

Poulin, R. (1997). Species richness of parasite assemblages: evolution and patterns. Annual Review of Ecology and Systematics 28: 341-358. https://doi.org/10.1146/annurev. ecolsys.28.1.341

Preston, F.W. (1948). The commonness, and rarity, of species. Ecology 29: 254-283. https://doi.org/10.2307/1930989

Ren, T.G., Guo, X.G. \& Jin, D.C. (2014). Two new species of chigger mites in the Genus Gahrliepia (Acari: Trombiculidae) from China. Pakistan Journal of Zoology 46: 1657-1662.

Rohde, K. (1993). Ecology of marine parasites. Helgoländer Meeresuntersuchungen 37: 5-33.

Rothenburger, J.L., Himsworth, C.G., Treuting, P.M. \& Leighton, F.A. (2015). Survey of cardiovascular pathology in wild urban Rattus norvegicus and Rattus rattus. Veterinary Pathology 52: 201-208. https://doi.org/10.1177/0300985814528220

Saburova, M.A., Polikarpov, I.G. \& Burkovsky, I.V. (1995). Spatial structure of an intertidal sandflat microphytobenthic community as related to different spatial scales. Marine Ecology Progress Series 129: 229-239. https://doi.org/10.3354/ meps129229

Samuel, P.P., Kamarasu, K., Govindarajan, R., Selvam, A., Leo, V.J. \& Arunachalam, N. (2017). Preliminary investigation on the prevalence of scrub typhus vectors in Krishnagiri district, Tamil Nadu, India. Journal of Advanced Zoology 38: 128-132.

Schoof, H.F. (1948). Common ectoparasites of the Norway rat, Rattus Norvegicus (erxl.), in North Carolina and the effects of 10 percent DDT dust treatments in their control and upon the serology of the rat. Journal of the Elisha Mitchell Scientific Society 64: 208-215.
Stekolnikov, A.A. (2013). Leptotrombidium (Acari: Trombiculidae) of the world. Zootaxa 3728: 1-173.

Sun, Y., Shi, C., Li, X.L., Fang, L.Q. \& Cao, W.C. (2018). Epidemiology of scrub typhus and influencing factors in Yunnan Province, 2006-2013. Chinese Journal of Epidemiology 39: 5457. https://doi.org/10.3760/cma.j.issn.0254-6450.2018.01.011

Vercammen-Grandjean, P.H. \& Langston, R. (1976). The chigger mites of the world (Acarina: Trombiculidae \& Leeuwenhoekiidae). volime III. Leptotrombidium complex. San Francisco: George Williams Hooper Foundation, University of California.

Walsh, M.G. (2014). Rat sightings in New York City are associated with neighborhood sociodemographics, housing characteristics, and proximity to open public space. PeerJ 2: e533. https://doi.org/10.7717/peerj.533

Wang, R.L., Wen, G., Liu, Y., Luo, J.D., Li, Q., Wang, M.T. \& Lin, S. (2019). Spatial distribution pattern of kiwifruit canker disease on 'Xuxiang' in field. Chinese Agricultural Science Bulletin 35: 88-92.

Wen, T.H. (1984). Sand mites of China (Acariformes: Trombiculidae \& Leeuwenhoekiidae). Shanghai: Xue Lin Publishing House, pp. 1-370.

Wu, G., Zhang, Y., Guo, H., Jiang, K. \& Gan, Y. (1996). The role of Leptotrombidium scutellare in the transmission of human disease. Chinese Medical Journal 109: 670-673.

Xu, Y.H. (1991). Southwest Climate. Beijing: Meteorology Press, pp. 1-297.

Xue, J., Zhou, G.Z. \& Liu, Y.X. (2004). The faunal study of chigger mites in Shandong Province. Chinese Journal of Vector Biology and Control 15: 452-454.

Ya, H.X. \& Zhang, Y.Z. (2016). Cases with coinfected hemorrhagic fever with renal syndrome and scrub typhus in Yunnan, China. Chinese Journal of Zoonoses 32: 266-270.

Yang, H.Q., Li, H.L., Wang, X., Li, C., Zheng, Y., Wei, Y.W., Yang, N. \& Ma, Y. (2014). Cluster analysis on chigger mites in Qinghai Province. Chinese Journal of Control of Endemic Diseases 29: 241-243.

Yao, H.W., Wang, Y.X., Mi, X.M., Sun, Y., Liu, K., Li, X.L., Ren, X., Geng, M.J., Yang, Yao, H., Wang, Y., Mi, X., Sun, Y., Liu, K., Li, X., Ren, X., Geng, M., Yang, Y., Wang, L., Liu, W. \& Fang, L. (2019). The scrub typhus in mainland China: spatiotemporal expansion and risk prediction underpinned by complex factors. Emerging Microbes \& Infections 8: 909-919. https://doi.org/10.1080/22221751.2019.1631719

Young, S.S. \& Wang, Z.J. (1989). Comparison of secondary and primary forests in the Ailao Shan Region of Yunnan, China. Forest Ecology and Management 28: 281-300. https://doi.org/ 10.1016/0378-1127(89)90008-X

Yu, X.J. \& Tesh, R.B. (2014). The role of mites in the transmission and maintenance of Hantaan virus (Hantavirus: Bunyaviridae). Journal of Infectious Diseases 210: 1693-1699. https://doi.org/10.1093/infdis/jiu336

Zhang, S.Y., Wu, D., Guo, X.G. \& Men, X.Y. (2007). Preliminary research on community and evolution ecology of fleas on small mammals of 19 counties in Yunnan, China. International Journal of Medical Parasitic Diseases 34: 231-234.

Zhan, Y.Z., Guo, X.G., Speakman, J.R., Zuo, X.H., Wu, D., Wang, Q.H. \& Yang, Z.H. (2013). Abundances and host relationships of chigger mites in Yunnan Province, China. Medical and Veterinary Entomology 27: 194-202. https://doi.org/ 10.1111/j.1365-2915.2012.01053.x

Zuo, X.H. \& Guo, X.G. (2011). Epidemiological prediction of the distribution of insects of medical significance: comparative distributions of fleas and sucking lice on the rat host Rattus norvegicus in Yunnan Province, China. Medical and Veterinary Entomology 25: 421-427. https:// doi.org/10.1111/j.1365-2915.2011.00948.x 
Appendix. Name list of chigger species identified from Rattus norvegicus

Family Trombiculidae (Ewing, 1929)

Subfamily Trombiculinae Ewing, 1929

Genus Leptotrombidium Nagayo et al., 1916

L. scutellare (Nagayo et al., 1921) $(88,6.22 \%)^{* *}$

L. sinicum Yu et al., 1981 (4, 0.28\%)

L. hiemalis Yu et al., 1982 (3, 0.21\%)\#

L. cricethrionis Wen, Sun et Sun, 1984 (6, 0.42\%)

L. shuqui Wen et Xiang, 1984 (45, 3.18\%)

L. wangi Yu et al., 1986 (54, 3.82\%)\#

L. densipunctatum Yu et al., 1982 (22, 1.56\%)\#

L. yongshengense Yu et Yang, 1986 (11, 0.78\%)\#

L. yui (Chen et Hsu, 1955) (16, 1.13\%)*

L. deliense (Walch, 1922) (1,0.07\%)\#**

L. xiaguanense Yu et Yang, 1981 (2, 0.14\%)\#

L. imphalum Vercammen-Grandjean et Langston, 1976 (32, $2.26 \%) \# *$

L. spicanisetum Yu et al., 1986 (1, 0.07\%)\#

L. cuonae Wang, Pan et Yan, 1996 (1, 0.07\%)\#

L. wenense Wu et al., 1982 (30, 2.12\%)\#**

L. qujingense Yu et al., 1981 (1, 0.07\%)\#

L. jinmai Wen et Xiang, 1984 (3, 0.21\%)

L. nudisensillum Yu et al., 1981 (18, 1.27\%)\#

L. longimedium Wen et Xiang, 1984 (1, 0.07\%)\#

L. akamushi Barumpt, 1910 (86, 6.08\%)*

L. trapezoidum Wang et al., 1981 (2, 0.14\%)\#

L. allosetum Wang et al., 1981 (1, 0.07\%)\#

L. pallidum (Nagayo et al., 1919) (1,0.07\%)\# *

L. sinotupaium Wen et Xiang, 1984 (25, 1.77\%)

L. ushi Yu, Yang et Gong, 1986 (3, 0.21\%)\#

L. intermedium Nagayo et al., 1920 (13, 0.92\%)\#

L. biji Wen et Xiang, 1984 (3, 0.21\%)\#

L. kitasatoi (Fukuzum et Obata, 1950) (1, 0.07\%)

L. huangdi Wen et Zhang, 1984 (9, 0.64\%)\#

L. baoshui Wen et Xiang, 1984 (29, 2.05\%)\#

L. rupestre Traub et Nadchatram, 1967 (2, 0.14\%)\# *

L. bambicola Wen et Xiang, 1984 (1, 0.07\%)

L. insulare Wei et al., 1989 (6, 0.42\%)**

L. shanghaense Wen et Lu, 1984 (1, 0.07\%)

L. taishanicum Meng et al., 1983 (2, 0.14\%)

L. heiense Wen, 1984 (1, 0.07\%)\#

L. turdicola Vercammen-Grandjean et Langston, 1976 (9, 0.64\%)\#

L. bengbuense Chen et Fan, 1981 (43, 3.04\%)
Genus Trombiculindus Radford, 1948

T. bambusoides Wang et Yu, 1965 (4, 0.28\%)

Genus Neotrombicula Hirst, 1925

N. japonica (Tanaka et al., 1930) (6, 0.42\%)\#

Genus Helenicula Audy, 1954

H. simena (Hsu et Chen, 1957) (29, 2.05\%)

Genus Cheladonta Lipovsky et al., 1955

C. micheneri Wen et Xiang, 1984 (8, 0.57\%)

Genus Ascoschoengastia Ewing, 1945

A. indica (Hirst, 1915) $(147,10.40 \%)^{*}$

A. yunnanensis Yu et al., 1980 (52, 3.68\%)\#

A. leechi (Domrow, 1962) (3, 0.21\%)

A. rattinorvegici Wen, 1984 (127, 8.98\%)

Genus Walchiella Fuller, 1952

W. notiala Yu et al., 1981 (25, 1.77\%)\#

Genus Herpetacarus Vercammen-Grandjean, 1960

H. aristoclavus Yu et al., 1979 (5, 0.35\%)\#

H. spinosetosus Wang et al., 1980 (7, 0.50\%)\#

H. callosciuri (Wen et Xiang, 1984) (1,0.07\%)\#

H. hastoclavus Yu et al., 1979 (23, 1.63\%)

Genus Euschoengastia Ewing, 1938

E. alpina Sasa et Jameson, 1954 (3, 0.21\%)\#

Subfamily Gahrliepiinae Womersley, 1952

Genus Walchia Ewing, 1931

W. micropelta (Traub et Evans, 1957) (10, 0.71\%)\#

W. chinensis (Chen et Hsu, 1955) (2, 0.14\%)\# *

W. koi (Chen et Hsu, 1955) (139, 9.83\%)

W. minuscuta Chen, 1978 (1, 0.07\%)\#

W. turmalis (Gater, 1932) (3, 0.21\%)\#

W. enode Gater, 1932 (6, 0.42\%)\#

W. ewingi (Fuller, 1949) $(215,15.21 \%) \#$

Genus Gahrliepia Oudemans, 1912

G. banyei Wen et Xiang, 1984 (18, 1.27\%)\#

G. madun Wen et Xiang, 1984 (3, 0.21\%)

(Note: The species marked with "\#", "**" and "*" were the newly recorded species from R. norvegicus in comparison with the previous study, the main vectors and the subordinate or potential vectors of scrub typhus in China, respectively. The figures in parentheses were the individuals and the constituent ratios of the mites collected). 